\title{
Speed Control of PMDC Motor using PID Controller
}

\author{
Muaz Abdel Rahman Ismail ${ }^{1}$, Eltahir Mohamed Heessain ${ }^{2}$ \\ ${ }^{1}$ Juba University, Department of Electronics, College of Applied and Industrial Science. Sudan \\ ${ }^{2}$ Department of Biomedical Engineering, Sudan university of Science and Technology, ALsahva zalt road, Khartom, Sudan
}

\begin{abstract}
PMDC motor using PID controller. PMDC Motor and Mat lab/ Simulink were used to design the transfer function and simulate PMDC Motor with and without Load, a with PID controller.The also study was discussing the performance of PMDC Motor; it found that the PI have the best perform.
\end{abstract}

Keywords: PMDC Motor, PI controller, PID Controller, Ziegler - Nichols method, control speed

\section{Introduction}

DC (Direct current) Motor is an electrical transducer that converts the electrical energy in to mechanical energy DC motor used in industrial applications, robotics application, steel rolling, mills and railways. the advantage of DC motor that are less complexity, less precise and wide range speed mode for various operate in many applications. For the operation on a wide range of speed it needs a controller to control the speed of the motor to perform the desired job and we need to eliminate the effect of disturbance that changes the speed.

Many control methods have been developed to reduce the effect of disturbance such as classical control, state - space method, state feedback and optimal control but it do not give good solution for reducing the effect of disturbance.

PID controller is one of the best advantage method for solving problems raised due to variation in parameter of system and environmental condition, PID controller are simply, quickly and more reliable solution over classical control and pole placement. The PID is a more robust control method then classical [4].

In this paper proposed a PID controller and it tested for various types of PID controllers. The designed Simulink model of PID controller for speed control of PMDC motor tested for various types of PID controllers, and found that for all types of PID the PI operate efficiently and gives better result to improve the speed control of PMDC motor in best time.

\section{Previous Studies}

2.1Prabha Malvinas (PG Student), Menka Dubey (Sr. Asst. Prof)

The paper shows various method of speed control of DC Motor and many techniques for tuning PID controller [9].

2.2 Wasif Abdel Aziz Saluos, Mohammed Abdel Karatim Alia the Gain scheduling ware implemented in PID controller to drive a DC Motor. The paper show the improved of the response system and eliminate the over shoot speed of Motor [10].

\subsection{Lokesh Kumaral}

The paper introduced an artificial neural network in PID controller to control DC Motor. It prepares the neural network as solution to reduce the rise time and peak over shoot.

\section{The Mathematical Model of PMDC Motor}

A DC motor consists of electrical and mechanical equation described as:

Air gap flux given as.

$$
\emptyset=K_{f} I_{f}
$$

The torque developed by the motor is given as.

The back emf of the motor

$$
T_{m}=K_{t} I_{a} \emptyset
$$

$$
e_{b}=k_{b} \omega_{m}
$$

Taking Laplace transform will get that

$$
E_{b}(s)=K_{b} S(\theta)
$$

General equation of PMDCM is given as:

$$
V_{a}=R_{a} I_{a}+L_{a} \frac{d I_{a}}{d t}+E_{b}
$$

Taking Laplace transform for equation (5).

$$
V_{a}=R_{a} I_{a}(s)+s L_{a} I_{a}(s)+E_{b}(s)
$$

From equation (4) and (6) we get .

$$
\begin{aligned}
& V_{a}(s)=R_{a} I_{a}+s L_{a} I_{a}(s)+K_{b} s \theta \\
& I_{a}(s)\left(R_{a}+s L_{a}\right)=V_{a}(s)-K_{b} s \theta(s)
\end{aligned}
$$

The Load torque equation is given as:

$$
J \frac{d^{2} \theta}{d t^{2}}+f \frac{d \theta}{d t}=T_{m}=K_{t} I_{a}
$$

Take Laplace transform for both side of equation (9)

$$
\left(J s^{2}+f s\right) \theta(s)=T_{m}(s)=k_{T} I_{a}(\mathrm{~s})
$$

From equation (10) I_a is given as.

From equ. (8) and (11) we get

$$
I_{a}(s)=\frac{T_{m}}{k_{T}}=\frac{\left(J s^{2}+f s\right) \theta(s)}{k_{T}}
$$




$$
\begin{gathered}
\frac{\left(J s^{2}+f s\right)\left(R_{a}+s L_{a}\right) \theta(s)}{K_{T}}=V_{a}(s)-K_{b} s \theta(s) \\
V_{a}(s)=\frac{\left(s^{2}+f s\right)\left(R_{a}+s L_{a}\right) \theta(s)}{K_{T}}+K_{b} s \theta
\end{gathered}
$$

From equation (13)

Where

$$
\frac{\theta(s)}{V_{a}(s)}=\frac{K_{T}}{\left(J s^{2}+f s\right)\left(R_{a}+s L_{a}\right)+s k_{b}}
$$

$R_{a}=$ Armature resistance $(\Omega)$. $L_{a}=$ Armature inductance $(H)$. $I_{m}=$ Motor of intertia $\left(\mathrm{Kg} \cdot \mathrm{m}^{2} / \mathrm{s}^{2}\right)$. $K_{b}=$ motor constant. $f=$ Daming frication coefficient.

\section{Dynamic Model of Direct Current Motor}

The motor connected with dynamical Load repesentited on figure (1).
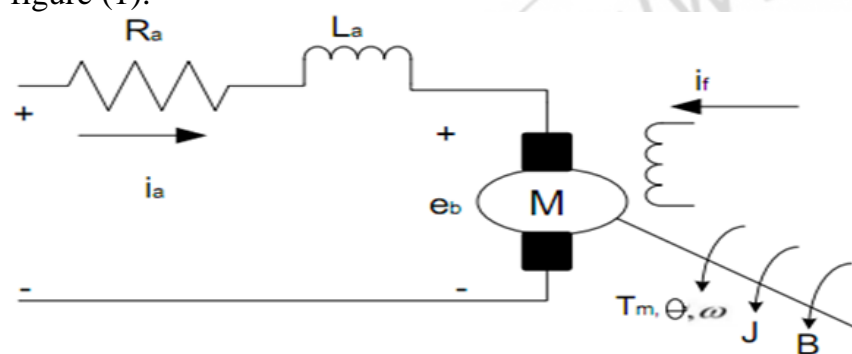

Figure 1: Show the electrical circuit of PMDC Motor with Dynamic Load

\section{PID controller (proportional, integral, and derivative controller)}

PID controller is a proportional _integral _derivative controller used ,In many industrial control systems. It is control loop feedback mechanism, that continuously calculates an error value as the difference between measured process variable value and set point the job of controller is to minimize the error over time by adjustment the control variable .the PID controller used when the system affected by disturbance and it has given better result if its tuned properly.

The proportional, integral, and derivative terms are added together to calculate the output of the PID controller.

The Proportional value determines the reaction to the current error, the Integral value determines the reaction based on the sum of recent errors, and the Derivative value determines the reaction based on the rate at which the error has been changed, figure 2 represent the close lop system with PID controller

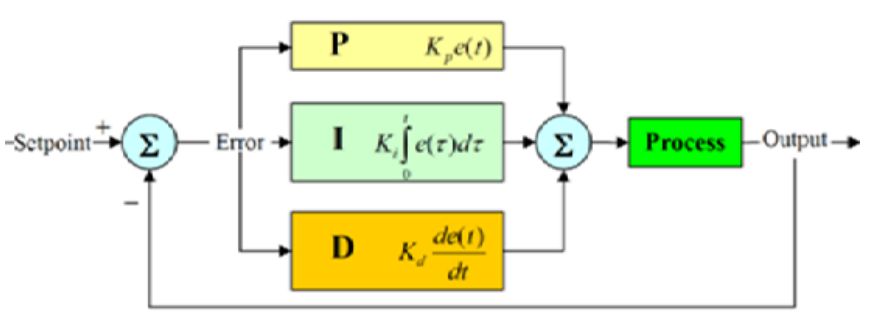

Figure 2 show the close loop system with PID controller

Defining $u(t)$ as the controller output, the final form of the PID algorithm is:

$$
u=K_{p} e+K_{r} \int e d t+K_{D} \frac{d e}{d t}
$$

\subsection{The characteristics of $P$, I, and $D$ controllers}

A proportional controller $(\mathrm{Kp})$ will have the effect of reducing the rise time and will reduce it, but never eliminate, the steady state error.

An integral control (Ki) will have the effect of eliminating the steady-state error, but it may make the transient response worse. A derivative control $(\mathrm{Kd})$ will have the effect of increasing the stability of the system, reducing the overshoot, and improving the transient response [7].

Effects of each of controllers $\mathrm{Kp}, \mathrm{Kd}$, and $\mathrm{Ki}$ on a closedloop system are summarized in the following table (1).

Table 1: The characteristics of $\mathrm{P}, \mathrm{I}$, and D controllers

\begin{tabular}{|c|c|c|c|c|}
\hline $\begin{array}{c}\text { CL } \\
\text { RESPONSE }\end{array}$ & RISE TIME & $\begin{array}{c}\text { OVERS } \\
\text { HOOT }\end{array}$ & $\begin{array}{c}\text { SETTLING } \\
\text { TIME }\end{array}$ & S-S ERROR \\
\hline Kp & Decrease & Increase & Small Change & Decrease \\
\hline Ki & Decrease & Increase & Increase & Eliminate \\
\hline Kd & Small Change & Decrease & Decrease & Small Change \\
\hline
\end{tabular}

5.2 Tuning of PID controller by using Ziegler - Nichols method.

Ziegler - Nichols method is one of more effective methods that up the usage of PID controller in industrial control systems. It continuous cycling method to tuning controller, based on trial and error procedure that as:

- Run the controller by taking only $(\mathrm{Kp})$ the other (Ki) and ( $\mathrm{Kd})$ is zero.

- Increase Kp value until the system is oscillation.

- Take controller gain over time period[1].

- The loop- tuning constants of the PID controller tabulated in table(2).

Table 2: Ziegler - Nichols tuning method Ziegler-Nichols method giving $K^{\prime}$ values (loop times considered to be constant and equal to dT)

\begin{tabular}{|c|c|c|c|}
\hline Control Type & Kp & Ki $^{\prime}$ & Kd' \\
\hline$P$ & $0.50 K_{c}$ & 0 & 0 \\
\hline$P I$ & $0.45 K_{c}$ & $1.2 K_{p} \mathrm{dT} / P_{c}$ & 0 \\
\hline$P I D$ & $0.60 K_{c}$ & $2 K_{p} \mathrm{dT} / P_{c}$ & $K_{p} P_{c} /(8 \mathrm{dT})$ \\
\hline
\end{tabular}




\section{International Journal of Science and Research (IJSR) \\ ISSN (Online): 2319-7064}

Index Copernicus Value (2013): 6.14 | Impact Factor (2015): 6.391

\section{Matlab/Simulink}

\subsection{Matlab/System model of DC Motor without Load:}

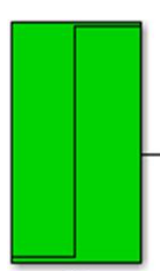

V

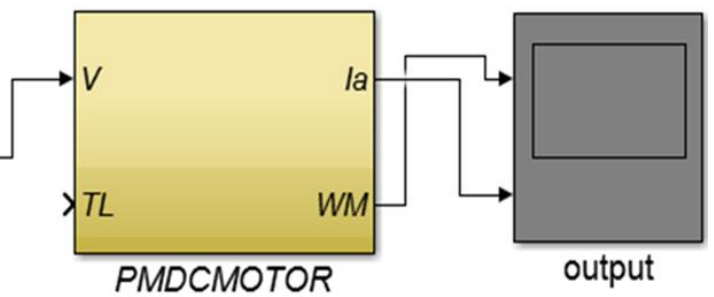

Figure 3: Matlab/simulink model of PMDCM without load

The figure 3 show the simulink model PMDC Motor using step signal to represent the volatge input and the output are current and speed.

\subsection{Matlab/Simulink model of PMDC Motor with PID controller}

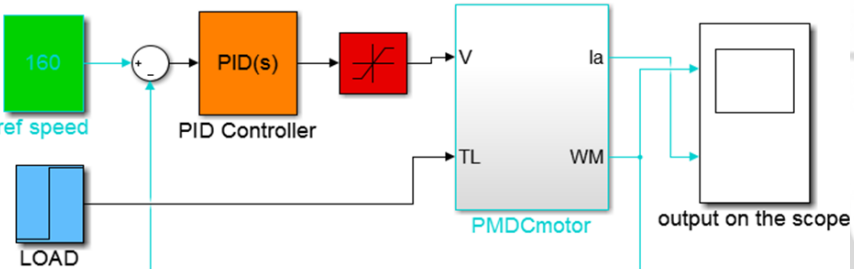

Figure 4: Matlb/simulink model of PMDCM with PID controller

This is figure 4. Shows Simulink model of controlled DC motor using PID controller for controlling DC motor speed. the DC motor drive mechanical Load characterized by inertia $\mathbf{J}$, Load torque $\mathrm{T}_{-} \mathrm{L}$ and friction coefficient $\mathrm{f}_{-}$. The (PID) controlled the speed of DC motor through loop ,that senses the actual speed of DC motor and compared with reference speed,the different between the actual and reference speed determine the armature current required by DC motor.

\section{Results and Discussion}

Real parameters are used in Simulink model of PMDC motor, and find out the Simulink responses for MPDC motor without Load and with Load. After that insert the various types of the PID controllers to the Simulink model of DC motor with same parameter.

The Simulink response of figure 5. shows the rise time is 8.5 second, settling time is 10 second and the speed $140(\mathrm{rad} / \mathrm{sec})$ when DC motor without Load as we see that the motor take long time to reach steady state response also current take 8 second to decrease.

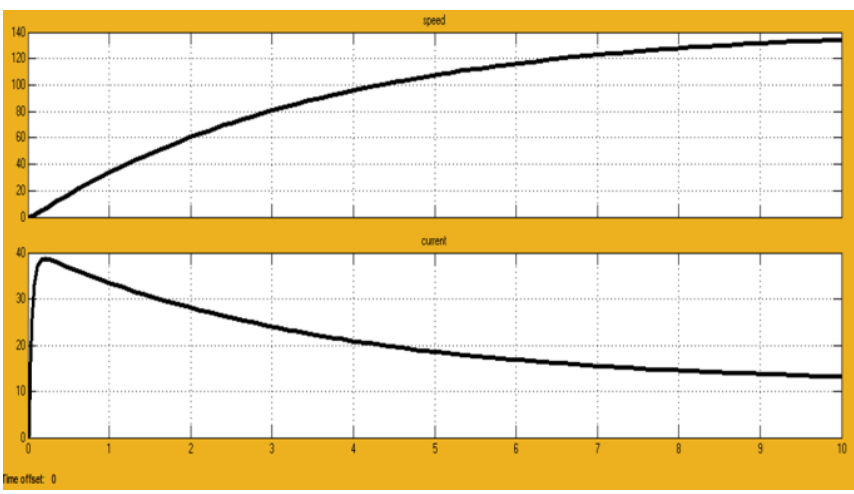

Figure 5: Simulink response of PMDC Motor without Load

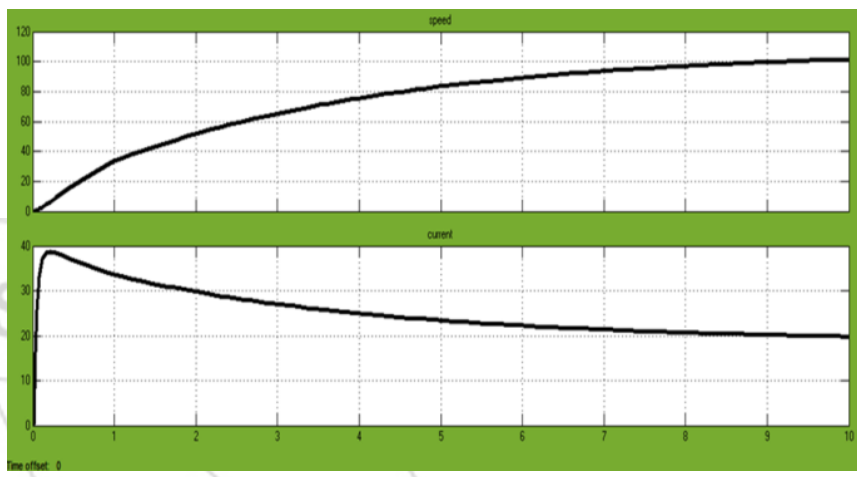

Figure 6: Simulink response of PMDC Motor with Load

Simulink response of figure 6 Show the PMDC Motor the speed is decrease from $140(\mathrm{rad} / \mathrm{sec})$ on figure.5 to $100(\mathrm{rad} / \mathrm{sec})$ when it is Load by $(2 \mathrm{Nm})$. And the current increase by $50 \%$, the rise time is 9 second and settling time is 10 second. So DC motor is effect by disturbances.

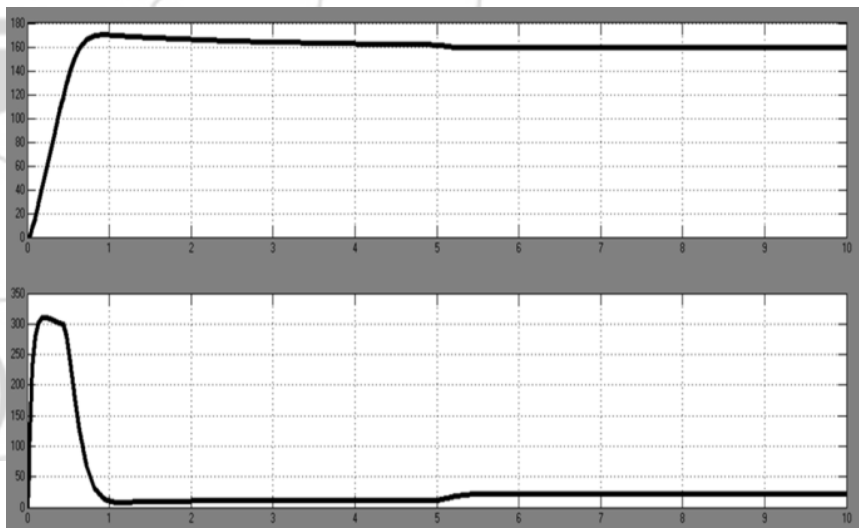

Figure 7: Simulink response of PID controller for TL (2Nm) and speed $(160 \mathrm{rad} / \mathrm{sec})$

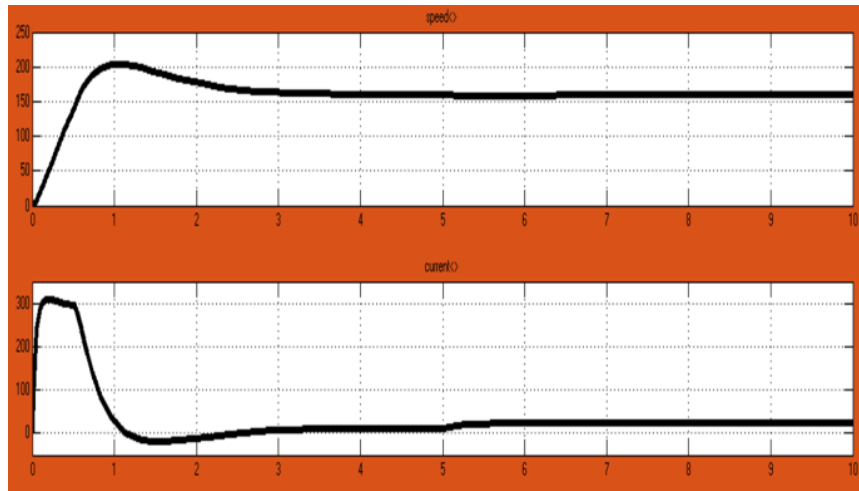

Figure 8: Simulink response of PI controller for TL $(2 \mathrm{Nm})$ a 


\section{International Journal of Science and Research (IJSR) \\ ISSN (Online): 2319-7064}

Index Copernicus Value (2013): 6.14 | Impact Factor (2015): 6.391

Figure 8 Simulink response of PI controller for TL (2Nm) and speed $(160 \mathrm{rad} / \mathrm{sec})$

Simulink response of PID controller for constant torque $(2 \mathrm{Nm})$ and constant speed $(160 \mathrm{rad} / \mathrm{sec})$ is shown in figure (7) its shows that rise time of response is about $0.75 \mathrm{sec}$. It's have maximum over shoot at $\mathrm{t}=0.9 \mathrm{sec}$. after $\mathrm{t}=5 \mathrm{sec}$. it's give steady state response.

The response of PI controller is shown in figure.(8), its shows that rise time of response is about $0.8 \mathrm{sec}$. it's have maximum over shoot at $\mathrm{t}=1 \mathrm{sec}$. and after $\mathrm{t}=3.5$ its give steady state response.

For the validity of the result we find out Simulink response of PID and PI controller for constant Load and speed as shown in figures $(7-8)$. It's seen that the PID controller improved the transient response and the steady state of MPDC motor and the best for control speed is PI controll

\section{References}

[1] B.J. Chalmors, Influence of saturation in brushless permanent magnet drives .IEEE proc. B Elecyr: Power Appl vol. 139, no. 1, 1992R. Caves, Multinational Enterprise and Economic Analysis, Cambridge University Press, Cambridge, 1982. (book style)

[2] C. T Johnson and R.D. Lorenz, Experimental Identification of friction and its compensation in precise, position controlled mechanism. IEEE Trans. I nd, Applicat, vol . 28, no, E. 1992.H.H. Crokell, "Specialization and International Competitiveness," in Managing the Multinational Subsidiary, H. Etemad and L. S, Sulude (eds.), Croom-Helm, London, 1986. (book chapter style)

[3] H. Lehuy et, al, MATLAB Help, ver . 7.5, Math works, Inc., 2007. J. Geralds, "Sega Ends Production of Dreamcast," vnunet.com, para. 2, Jan. 31, 2001. [Online]. Available: http://nl1.vnunet.com/news/1116995. [Accessed: Sept. 12, 2004]. (General Internet site)

[4] Mohamed M. M. Negm, et al experimental investigation of speed control of dc motor based on optimal PID controller IEEE, pp-35-41, 2003.

[5] Moley Kutty George. Et. Al, speed control of separately excited dc motor. American Journal of applied sciences 5 (3) Science Publications ISSN $1546-$ 9239 -pp. 227- 233, 2008

[6] J. Zhang, N. Wang and S Wang, Developed method of tuning PID controllers fuzzy rules for integration process , Proceedings of American control conference, Boston, 2004 , pp. $1109-1114$,

[7] K. H. Ang ,G. Ch0ng and Y. Li , PID controller system analysis, design and technology, IEEE transaction on control system Technology, Vol. 13, No . 4, 2005, pp. 559- 576.

[8] Gopal , M. control systems - principles and Design .3rd Edition, New Delhi: Mc Graw - Hill , 2008.

[9] Prabha Malviya(PG Student), Menka Dubey (Sr. Asst. Prof) International Journal of Engineering sciences and Research Technology.
[10] Vo2.1NO. 8,2015

[11] Wasif Abdel Aziz Saluos, Mohammed Abdel Karatim Alia American journal of soft ware Engineering and Applications Vol.3 No. 6. 2014, pp. 102-105.

[12] Lokesh Kumaral .International journal of Recent Research aspects ISSN :2349.7688, vol. 1, Issue 3, December 2014. pp. 49-55. 